\title{
Planning and Designing of Letters and Calls Management System Based on E-government
}

\author{
Xie Zhenhua \\ School of Public Administration \\ Xiangtan University \\ Xiangtan, Hunan, China \\ E-mail: wuqingxiezhenhua@126.com \\ Zou Kai \\ School of Public Administration \\ Xiangtan University \\ Xiangtan, Hunan, China
}

\author{
Deng Chunlin \\ School of Public Administration \\ Xiangtan University \\ Xiangtan, Hunan, China \\ Zhou Bo \\ School of Public Administration \\ Xiangtan University \\ Xiangtan, Hunan, China
}

\begin{abstract}
Based on analysis of Chang-Zhu-Tan area online letters and calls problems, by letters and calls management system as the research object, with electronic government network and service concept to provide support, to enhance the government and the public communication level, strengthen supervisory, and promote business transparency oriented, the paper through internal analysis and planning the construction of the letters and calls management system to put forward the system structure, according to the function module and the structure, design to the system, for letters and calls to design a convenient, efficient, high-quality management system to provide reference.
\end{abstract}

Key words-letters and calls management system; system planning and designing; e-government

\section{FOREWORD}

In recent years, with the rapid advance of China's reformation and development, and the various types of contradiction having become increasingly prominent, the letters and calls is confronted with serious challenges. Taking 1Q in 2007 letters and calls data in Hunan province as example, bureau for letters and calls of the province received 10153 letters from the masses, 2215 batches, 7550 visitors, increased by $49 \%, 12 \%$, 37\% over the same period last year. If ensuring early acceptance, early reporting, early treatment to letters and calls of the public, it will safeguard the interests of the masses and will greatly enhance the credibility of the government.

With the rapid development of e-government, China attaches great importance to the informationize construction for letters and calls. On May 1 , 2005, The State Department formally implemented "The Regulation for Letters and Calls of PRC",which is the newly promulgated. It has been written the target building "the whole nation information system for letters and calls" in among them ${ }^{[1]}$. The deputy director general $\mathrm{Xu}$ Lingyi in state bureau for letters and calls points out there must be information processing for letters and calls, so information work is an important part for letters and calls in attending the whole state letters and calls management system working conference on September 3, 2010 ${ }^{[2]}$. Designing the letters and calls management system to promote close contact with government and the public improves the efficiency, science and transparency of dealing with complaints, which become particularly important.

\section{ANALYSE THE CONTENTS OF LETTERS AND CALLS MANAGEMENT SYSTEM BASED ON E-GOVERNMENT}

\section{A. Current Situation of Letters and Calls Management System Based on E-government}

At present, with strong encouragement of the state bureau for letters and calls, the whole nation letters and calls information system has started working, so the informationize construction for letters and calls has already got first step effect. Abort building in the database aspect in November of 2008,the letters and calls data centre already has been established in common 27 provinces (area , city) and Xinjiang production and construction corps; abort network construction aspect the state letters and calls system has connected more than 1,800 county and more than 4,100 local departments; abort software application aspect, the country already accomplishes application software deployment, the state has completed the deployment of application software, the letters and calls system of 34 central ministries has been connected to the network of centers $^{\text {[3] }}$

But, there are still some imperfections in letters and calls management system. Mainly the following problems are: the first, the business applications of letters and calls management system is relatively simple. Taking Xiangtan of Hunan as example, the system only provides personal materials and reflects the condition to the public, not achieving the letters and calls work in its real meaning of informationize;the second, the supervision is not enough. Taking the information publicly available platform in Zhuzhou of Hunan as example, although it has finished Network of government work, but the council is not open to the public, the public can not be a detailed understanding of the processes for the letters and calls, lacking the supervision for the letters and calls; the third, the communication of the public and functional departments is not strong enough. Taking the letters and calls online in Changsha of Hunan as example, it only conveys the letters and calls problem to relevant functional departments, Did not show the 
attitude of the functional departments. When the public comes across a question, they could not timely communicate with it. The letters and calls management system not only cannot meet the needs of the office for letters and calls, also cannot meet the diversified needs of the public petition. So, the letters and calls management system based on e-government came into being.

\section{B. The Characteristics of Letters and Calls Management System Based on E-government}

The letters and calls management system based on e-government is the legal, convenient and efficient demanding platform and the service platform for solving the public problems, stabling the social development and enhancing the credibility what can integrate the public complaints, the case processing and the process of supervision results feedback as one to meet the public demand and improve the quality for letters and calls, though combination of the process for letters and calls and e-government by the modern advanced information technology.

The letters and calls management system based on e-government have the following three features ${ }^{[4]}$. The first is that the public participates in the letters and calls convenient and rapid. The letters and calls management system may unified manage the business for letters and calls. If the letters and calls cases involve multiple departments, the relevant functional departments can coordinate for sharing of information resources and expediting processing of the complaint cases. The second is the openness of the supervision and evaluation. The higher authorities through the system can quickly and easily query all complaint cases of having been handled. There will not be a buck each of the various departments about reflecting by the public to the government departments. The third is transparency of the business for letters and calls. The letters and calls management system can full understand of the whole process to deal with letters and calls.

\section{The significance of Letters and Calls Management System Based on E-government}

The significance of the construction of letters and calls management system based on e-government contains: the first is in favor of government changing the concept of service for letters and calls: it changes the negative and buck attitude into public satisfaction as the standards of service concept; the second is in favor of optimizing the processes of dealing with the letters and calls: it changes the inefficient, time-consuming and wasting money workflow into the convenient, fast and efficient workflow; the third is in favor of promoting the democratic process of government dealing with the letters and calls: it changes the closed, the "secret operations" mode in the traditional government letters and calls into the new work mode of communicating with the public and accepting social supervision.

\section{PLANNING OF LETTERS AND CALLS MANAGEMENT SYSTEM BASED ON E-GOVERNMENT}

\section{A. System Planning Ideas}

The construction of the letters and calls management system should absorb the features of e-government what includes the public demand-oriented, timely services for the concept, intergradations and individuation, rely on the Internet, use of IT, Integrate of the government's management for letters and calls and service model, and achieve the process optimization for letters and calls. Thereby, it achieves the integration of government functions and the personalized service for letters and calls, for the government providing a great convenience and timeliness, and openness in government affairs and efficient regulatory ${ }^{[5]}$. The letters and calls management system is a product of the e-government, which broadens the channels for letters and calls, establishes a new electronic bridge between the public and the government, and play an active leading role in close contacting with the public, reflecting the society and public opinion, and improving the socialist democratic and political construction ${ }^{[6]}$.

\section{B. System Requirements Analysis}

The letters and calls management system based on e-government not only needs some of the basic functionality, listed as meeting the public, returning of the government and archiving statistics, but also needs to have the following higher level of demand: the first, improving the public and the departments to communicate effectively. The second, strengthening supervision for letters and calls. The third, promoting process transparent for letters and calls.

\section{DESIGNING OF LETTERS AND CALLS MANAGEMENT SYSTEM BASED ON E-GOVERNMENT}

\section{A. The goal of Designing System}

The goal is combining with e-government and the actual situation of the letters and calls, designing the high-quality letters and calls management system what can Conform the government business for letters and calls, and meet the public demand.

\section{1) Functional Objectives}

According to the needs of users and the requirements of letters and calls, the system should achieve the following three functions:

The surmising and querying features: the public should submit petitions to the system in accordance with their own needs. The system can timely sent the requirements of the public to the functional departments for effectively addressing the questions. The public can find out the news they are concerned with, announcements and the results of handle petitions by the system.

The classifying and processing functions: the staff in the first filters the petitions from the public to decide whether to accept, then classifies petitions in the property, finally transfers and assigns the government departments of dealing with the matter.

The monitoring and feedback functions: the functional departments can open the handling process to the public through the system, for Letting the public know the whole process. If presenting some questions, the public can use the system to provide feedback to the functional departments and the higher authorities. 
The reporting and statistical functions: if the public is not satisfied with the results, reported to the system. When the staff receives the report information, they will communicate with relevant government departments effectively, for the results acceptable to the public. The system also provides the statistical functions and the reliable data for the leaders' decision, improving the work and the efficiency of the government.

\section{2) The Performance Requirements}

In the course of the system could lead to the situation which many users access to upload files simultaneously. So, the performance of the system not only needs to have: quick running speed, high network bandwidth, big storage capacity, high security level, also needs to include the reliability: when the system fails, the system should restore the normal operation at the lowest cost, and minimum negative impact; the availability: the users should conveniently use the system; the maintainability: the maintainability of the system should be high; the portability: the system should be compatible with the latest and the highest version of the application server ${ }^{[7]}$.

\section{B. System Architecture}

The logical model of this system is based on analyzing and studying the letters and calls process of the government, overcomes the information barriers causing by not clearly the organization roles and responsibilities. We could create the architecture diagram through the communication of the information between the government and the users. Shown in figure 1.

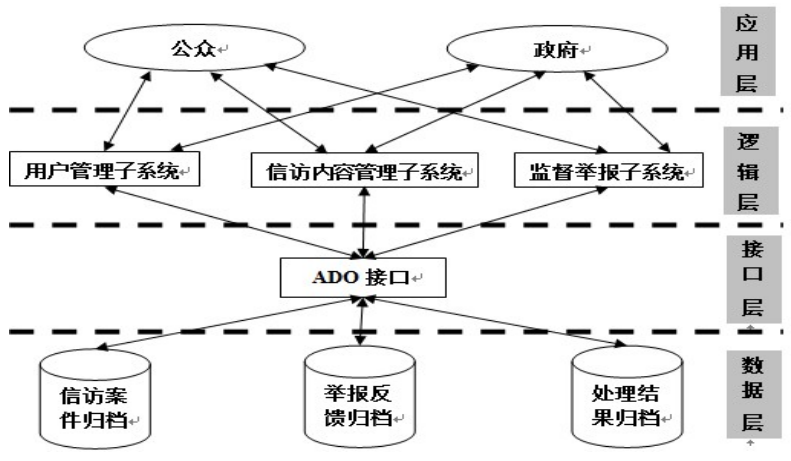

Figure 1 the system architecture diagram

The system is divided into four layers from bottom to top, respectively, the data layer, the interface layer, the logic layer and the application layer. The data layers: inducts and collects the process and results of letters and calls, and the public feedback and the evaluation; the interface Layer: This system is mainly to use ADO (ActiveX Data Objects) interface to access relational or non-relational data; the logical layers: it is the hub of the system, is abstracted the main business logic, up to provide support and service for the application layer, down through the ADO interface for the application layer calling the $r$ data resources from the data layer; the application layer: on the basis of the logical layer, provides the interface for complaining to the public, and provides a solution entrance for handling the letters and the calls cases to the government.

The system could closely link to the public, the institution for the letters and calls, and the government department. The government's internal system deliveries the letters and calls information for the institutions for the letters and calls, and the government departments. Shown in figure 2.

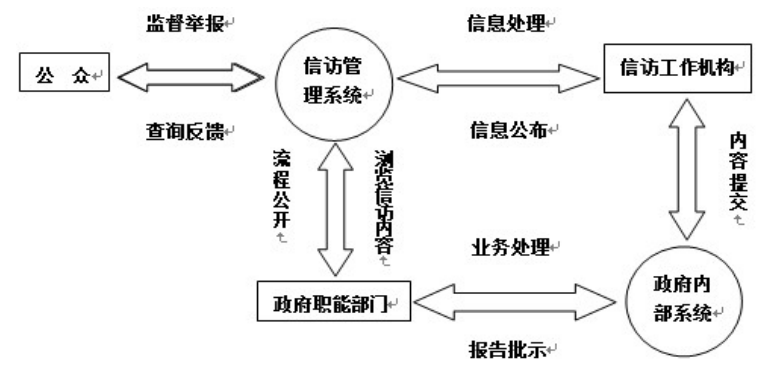

Figure 2 the system architecture

\section{Construction and Designing The Functional Modules}

1) The Function Structure Diagram

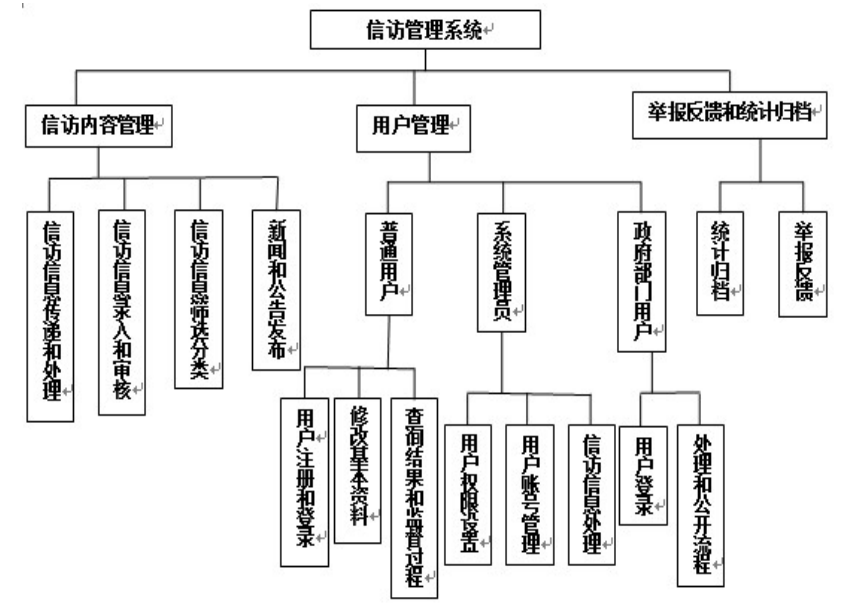

Figure 3 system function structure diagram

The main functional modules of the system are as follows:

The content management for the letters and calls: the main function of this module is to publish the news and announcements about the letters and calls, screen and classify the information and pass to the government departments. The government departments makes the processing and then passes the results to the ordinary user. Only the system administrators have this permission. The system administrator needs to perform the audit of the contents. Once approved, ordinary users can browse it. The system administrator can delete or modify the contents does not meet the standards.

The user management: this module needs to allocate the user permissions corresponding to the system. Users of the system is divided into three categories: the ordinary users, the government departments and the system administrators. The ordinary users need to register and then could modify their basic information, submit the questions and comments required the government to solve, oversight the process of the functional departments dealing with the letters and calls, query the response $\mathrm{t}$ the government making and feedback. The accounts of government departments is assigned by the system administrator. Its permission could visit the letters and calls question of the relevant departments and make a deal, timely pass the results to the system administrator, and public 
processes. The system administrator is the hub of the system. It not only generates and manages the user accounts, but also communicates with the ordinary users and the government departments for improve the efficiency of letters and calls.

The reporting on feedback and counting to the file: when the relevant government departments arises problems, the staff for the letters and calls reported to higher authorities or conferred with the department according to the nature of the problem, this module timely feedbacks the results to inform the ordinary user. the staff for the letters and calls on each petition process should count, evaluate and classify the database.

\section{2) The System Processes}

The basic processes is: the users can submit the content through the channel of letters and calls system according to their needs, And supervise and report the processes, and query feedback on the results. The office for letters and calls will submit the information, then answer, transfer or delete it according to the actual situation. The government departments will be transferred to the content, reply by the closing of Letters and Visits Office or system administrator, closed by the office or the administrator for letters and calls. Another press release function is an independent subsystem, Only the administrator has the permission to publish and manage the news.

The data flow diagram is shown in Figure 4.

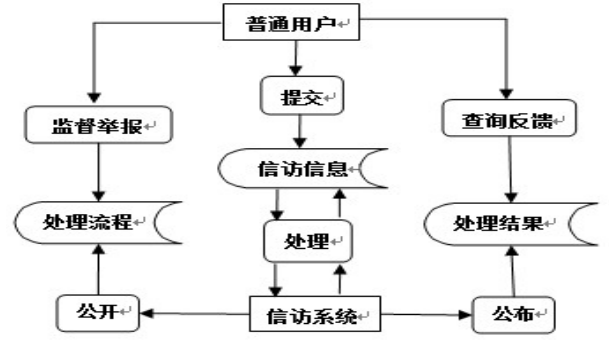

Figure 4 the system data flow diagram

\section{Designing The System Database}

The database tables involved in this system are: the informational tables of the letters and calls, the question, the government department, the attachment, the Replying letters and calls, the article, and so on. With the informational table of the letters and calls as an example Figure 5 as shown ${ }^{[8]}$.

\section{THE CONCLUSION}

The letters and calls based on e-government is a new form under the new situation. It broadens the channels for the mass. This channel is directly reflected in the letters and calls management system suitable for the local condition. The letters and calls management system in order to comply with the trend of the social development and the public administration of the government, needs to improve and perfect constantly in the practical application, to provide better help for the letters and calls, let the public more quickly and easily receive the information, and greatly promote the operational efficiency of all aspects of the government letters and calls. At last, it makes a significant contribution to the harmonious development of the society.

\begin{tabular}{|c|c|c|c|}
\hline 列名 & 数据类型 & 可否为空 & 说明 \\
\hline letter_id & Uniqueidentifier & NOT NULL & 信访函编号 \\
\hline letter_subject & Varchar & NOT NULL & 主题 \\
\hline letter_content & Text & NOT NULL & 内容 \\
\hline letter_question_name & Varchar & NOT NULL & 问题类型 \\
\hline letter_name & Varchar & NOT NULL & 公众姓名 \\
\hline letter_subtime & Datetime & NOT NULL & 提交时间 \\
\hline letter_acceptnum & Varchar & NULL & 受理号 \\
\hline letter_progress & Varchar & NOT NULL & 处理过程 \\
\hline letter_department_name & Varchar & NOT NULL & 信访受理部门 \\
\hline letter_person_name & Varchar & NOT NOLL & 信访受理人姓名 \\
\hline letter_person_phone & Varchar & NOT NULL & 信访受理人电话 \\
\hline letter_Process & Varchar & NOT NULL & 信访受理流程 \\
\hline letter_settime & Datetime & NULL & 立案时间 \\
\hline letter_ctime & Datetime & NULL & 结案时间 \\
\hline letter_from & Varchar & NOT NULL & 信访来源 \\
\hline letter_email & Varchar & NOT NULL & 电子邮箱 \\
\hline letter_phone & Varchar & NOT NULL & 联系电话 \\
\hline
\end{tabular}

Figure 5 The informational table of the letters and calls

\section{ACKNOWLEDGEMENTS}

This paper relies on the general project of the department of education in Hunan: The study of performance evaluation of the electronic letters and calls in the local government to changzhutan for example(10C1284). It had completed based on the research of online letters and calls in Chang-Zhu-Tan. So, sincerely thanking for the team members of the project and the department for letters and calls in Chang-Zhu-Tan.

\section{REFERENCES}

[1] The state council of the People's Republic of China The People's Republic of China Petition regulations, 2005[2005-05-23]. http://www.gov.cn/zwgk/2005-05/23/content_271.htm.

[2] National Working meeting of Petition system,2010[2010-09-10]. http://www.gjxfj.gov.cn/gzyw/2010-09/10/c_13489210.htm.

[3] Guan Li,National letters and information system the first batch of promotion application unit symposium held in Beijing,People's letters and calls, January2009(In Chinese).

[4] Liao Xiaoming,Zhao Rong, Research and Development of Petition Management System based on E-government,Chinese Public Administration, Vol07,pp.55-57,July2009(In Chinese).

[5] Kolsoom Abbasi Shahkooh, A strategy-based model for e-government Planning,Computer Software and Applications Conference,2007(In USA)

[6] Zhu Ying,A Study on the Problems and Strategies in Pushing Forward the E-ombudsman of the Chinese Government,Jilin university,2005(In Chinese).

[7] Dean Leffingwell,DonWidrig,Managing Software Requirements : A Unified Approach,Beijing-Machinery industry press,2002(In Chinese).

[8] Yang Hu,Li Fenglei,Wang Bin,SQL Server 2005Data base system development case selection, Beijing-People's wiley\&sons press,2007 (In Chinese) 